\title{
Characterization of Submicron Oil Mist Particles Generated by Metal Machining Processes
}

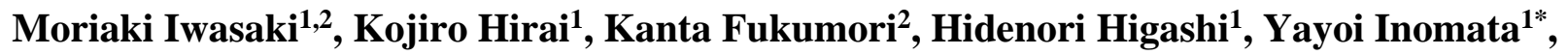 \\ Takafumi Seto ${ }^{1}$
}

${ }^{1}$ Kanazawa University, Kanazawa 920-1192, Japan

${ }^{2}$ Sanki Engineering Co., Ltd., Kanagawa 242-0007, Japan

\begin{abstract}
The number size distributions of submicron oil mist particles generated by three industrial metal (steel) machining processes - lathe machining, cutting, and grinding-were measured using an electrical mobility analyzer and an optical particle spectrometer. The measured number concentration of ultrafine particles (UFP; $\sim 30$ nm diameter) reached $10^{7}$ particles $\mathrm{cm}^{-3}$ during each machining process. The condensation of thermally evaporated oil vapor was considered to be a major route of ultrafine particle generation during lathe machining and grinding, which used an oil-in-water emulsion and an insoluble lubricant oil, respectively. Cutting, which did not use lubricant oil, also produced a steep increase in the number concentration of UFP; these particles may have formed from residual oil-in-water emulsion on the surface of the workpiece after lathe machining. A simplified numerical simulation was used to quantify the particles arising from machining and leakage when the apparatus was opened. Although local ventilation effectively reduced the concentration of the oil mist in the apparatus and prevented the diffusion of this substance when the apparatus door was opened, leakage was observed when the workpieces were exchanged; this leakage was attributed to entrained particles on the workpieces. Hence, countermeasures to prevent entrained oil mist are necessary to improve the air quality in working environments.
\end{abstract}

Keywords: Oil mist; Ultrafine particles; Fine particles; Workspace air quality.

\section{INTRODUCTION}

Oil mist is generated in machining plants, which consume large amounts of oil for lubricating and cooling cutting tools and workpieces. Oil mist is defined as microscale airborne oil droplets generated by fast-moving machine parts and the condensation of vaporized oil substances (Jonathan and David, 2000). Also, oil mist is defined as colloid composed of solid-core particles such as metal and other elements surrounded by oil (Zhang et al., 2017). Oil mist emissions during the machining process increase the airborne particle concentration in the working environment and are associated with occupational health problems such as inflammation of skin, laryngeal cancer, asthma, and bronchial hyperresponsiveness (Mackerer, 1985; Robertson et al., 1988; Kubasiewicz et al., 1991; Ahrens et al., 1991; Massin et al., 1996; Kazerouni et al., 2000; Greg et al., 2001; Simpson et al., 2003). The Japan Society for Occupational Health recommends that the mass concentration of oil mist be maintained below

\footnotetext{
* Corresponding author.

Tel.: +81-76-234-4825

E-mail address: yinomata@se.kanazawa-u.ac.jp
}

$3 \mathrm{mg} \mathrm{m}^{-3}$ (Japan Society for Occupational Health, 2017); however, such mass-based regulations do not account for the effects of oil mist generated by gas-phase nucleation processes. The diameter of oil mist generally ranges from 10 to $10,000 \mathrm{~nm}$, and oil mist generated by evaporationcondensation processes contains a significant amount of ultrafine particles (UFP) with diameters of $100 \mathrm{~nm}$ or less (Greg et al., 2001; Kondo et al., 2011; Wang et al., 2011). UFP are very small compared with the cellsizes. The UFP may deposit readily in the airway and deep lungs. The UFP are considered to be associated with adverse health effects (Oberdörster, 2001; Donaldson et al., 2002).

Furthermore, high number concentrations of oil mist particles result in fog that reduces visibility in the machining plant workspace as light is scattered by aerosol particles, particularly those with diameters of approximately $100 \mathrm{~nm}$ (Hinds, 1999). There is great interest in understanding the number concentration of nanoscale airborne oil mist generated by machining in factory; however, measurements during real machining processes in factory are still limited.

In industrial-scale machining processes, equipment is usually operated in a closed apparatus with a local ventilation system. There have been some reports on the oil mist collection efficiency of air filtration units (Cucu and Lippold, 1985; Letts et al., 2003; Brahm, 2012); however, the 
effectiveness of nanometer-sized oil mist collection has yet to be investigated. Moreover, leakage of oil mist from the machine apparatus is another potential source of oil mist in machining workspaces. Because of tight requirements to improve production yield while reducing manufacturing cost, there is typically a very short time delay between completing the machining process and opening the apparatus door to replace work; therefore, significant amounts of oil mist may be exhausted from the apparatus door.

In this study, temporal changes in the size distribution of oil mist were measured in a large-scale factory that produces automobile parts. An electrical mobility analyzer and optical particle spectrometer were used to measure the particle size distributions of the exhaust and the air around the apparatus door of three typical metal machining processes: lathe machining, gear cutting, and gear grinding. Furthermore, a simple numerical simulation was created to quantify the oil mist particles that were generated by the processing equipment and leaked from the apparatus door when workpieces were exchanged.

\section{EXPERIMENTAL}

\section{Industrial Metal Machining Processes}

We investigated the oil mist generated by three typical machining processes: lathe machining (Fuji Corp.), gear cutting (Kashifuji Works, Ltd.), and gear grinding (Reishauer). Fig. 1(a) is a schematic of the lathe machining process, which is used to sharpen cylindrical objects. During lathe machining, the cutting tool was fixed perpendicular to the workpiece, which rotated at high speed (several thousand rev $\min ^{-1}$ ) and moved along the axial direction, and oil-inwater emulsion was continuously fed to the machining point through the oil transport tube to reduce the temperature of the workpiece. The spindle speed was $2,000 \mathrm{rev} \mathrm{min}^{-1}$ for

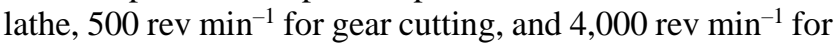
gear grinding, respectively. The feed rate of lathe machining tool was $0.35 \mathrm{~mm} \mathrm{rev}^{-1}$. The cutting oil was Sugicut CE18PF (Sugimura Chemical Industry Co., Ltd.) for lathe and Yushironcut NX-650T (Yushiro Chemical Industry Co., Ltd.) for gear grinding. Fig. 2 illustrates how large droplets are generated by the mechanical breakup of liquid film on the surface of the rotating object during lathe machining. Moreover, oil was also evaporated from the contact point between the workpiece and the cutting tool where the local temperature is increased by the mechanical friction. As the vapor was rapidly quenched to room temperature, nanometersized clusters were generated by the nucleation of the supersaturated oil vapor and grew to several tens to hundreds of nanometers by further condensation of oil vapor and the coagulation of droplets. These processes resulted in high concentrations of nanometer to micron-sized oil mist particles $\left(>10^{7}\right.$ particles $\left.\mathrm{cm}^{-3}\right)$.

Similar oil mist generation processes may occur during gear cutting and gear grinding, as shown in Figs. 1(b) and 1(c), respectively. During gear cutting, the hob (screw-type tool) contacted the metal-plate workpiece at a $90^{\circ}$ angle. During our experiments, machining oil was not supplied to the machining point because there was residual oil-in-water emulsion on the machining pieces after lathe machining; thus, gear cutting had the highest workpiece surface temperature of the three processes (measured by infrared camera). During gear grinding, a surface of the gear was smoothly polished with a helical grindstone. In this process, a large amount of water-insoluble oil was used to reduce the temperature of the contact area between the polishing tool and the workpiece. The vapor pressure of the water-insoluble oil was generally lower than that of the oil-in-water emulsion; however, UFP were generated by both processes.

\section{Experiments}

Fig. 3 is the industrial machining process apparatus and aerosol measurement system used in this study. Table 1 lists details of the system. The volumes of the three machining

(a) Lathe machining

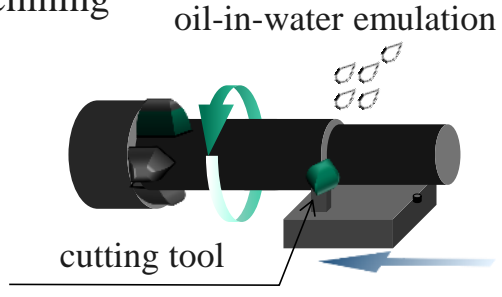

\section{(b) Gear cutting}

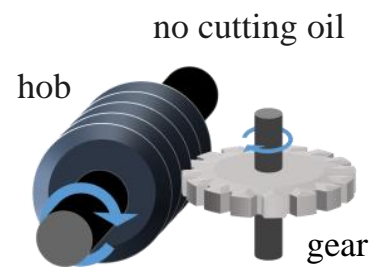

(c) Gear grinding

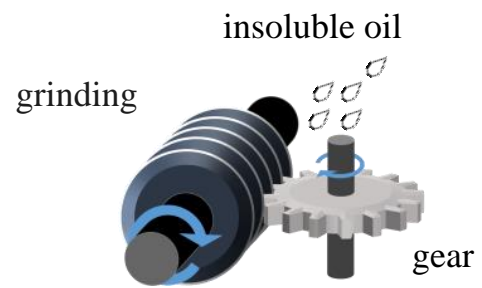

Fig. 1. Schematic diagrams of three industrial metal machining processes: (a) lathe machining, (b) gear cutting, (c) gear grinding. 


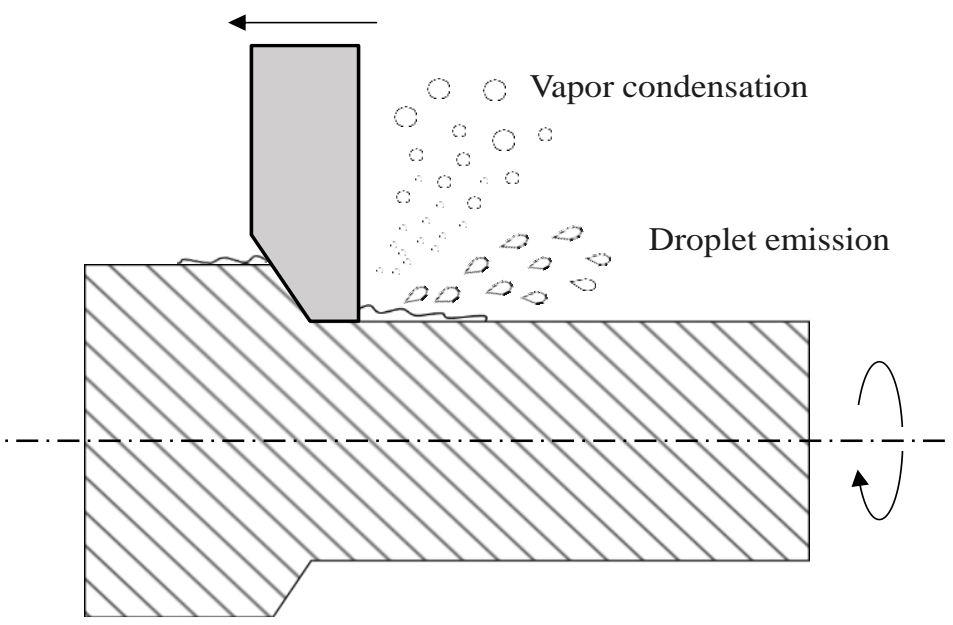

Fig. 2. Generation mechanism of oil mist: evaporation-condensation and mechanical breakup of the liquid film.

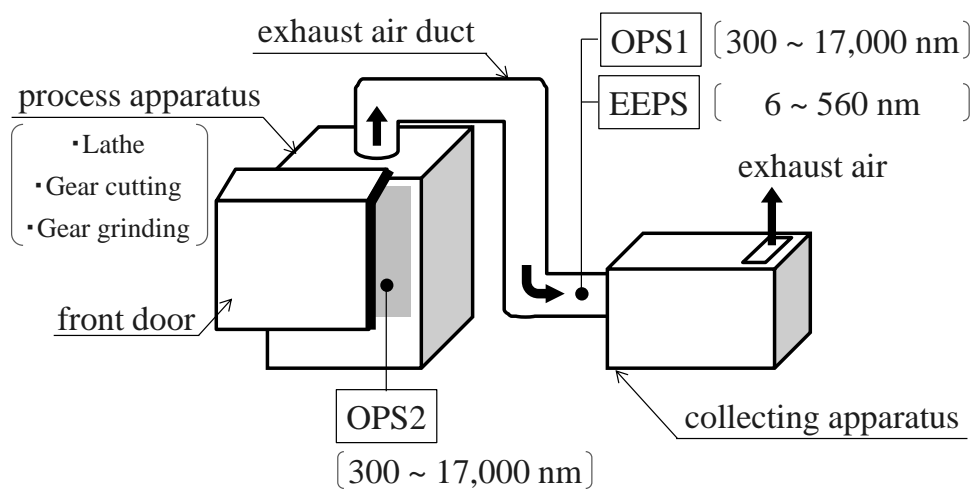

Fig. 3. Experimental setup.

Table 1. Experiment condition.

\begin{tabular}{llll}
\hline & Lathe machine & Gear cutting machine & Gear grinding machine \\
\hline Volume of process apparatus $\left[\mathrm{m}^{3}\right]$ & 1.0 & 2.0 & 3.8 \\
Exhaust duct length $[\mathrm{m}]$ & 5.0 & 5.0 & 5.0 \\
Exhaust duct diameter $[\mathrm{m}]$ & 0.150 & 0.150 & 0.198 \\
Exhaust air flow rate $\left[\mathrm{m}^{3} \mathrm{~s}^{-1}\right]$ & 0.05 & 0.29 & 0.31 \\
Air velocity in exhaust duct $\left[\mathrm{m} \mathrm{s}^{-1}\right]$ & 2.8 & 16.4 & 10.0 \\
\hline
\end{tabular}

units were $1.0 \mathrm{~m}^{3}$ (lathe), $2.0 \mathrm{~m}^{3}$ (gear cutting), and $3.8 \mathrm{~m}^{3}$ (gear grinding). As shown in Fig. 3, an air duct with a diameter of either 150 or $198 \mathrm{~mm}$ was connected to the machining process apparatus and air was evacuated from the apparatus by a pump attached to the collecting apparatus of the measurement system. The particles in the apparatus were flown into collecting apparatus. In the collecting apparatus, a centrifugal oil mist trap for the lathe and gear cutting machine and an electrostatic precipitator for the gear grinding machine were set. The position of the collecting apparatus was next to the processing equipment and the height is about $1.5 \mathrm{~m}$. The exhaust air released upwardly in the workspace. The length of the exhaust duct was $5 \mathrm{~m}$ for all units and the exhaust flow rates were $0.05,0.29$, and $0.31 \mathrm{~m}^{3} \mathrm{~s}^{-1}$ for the lathe, gear cutting, and gear grinding units, respectively (Table 1); the space time, $t_{\mathrm{s}}$, of the three units were $20.0 \mathrm{~s}$ (lathe), $6.9 \mathrm{~s}$ (gear cutting), and $12.3 \mathrm{~s}$ (gear grinding), respectively. It is noted that $t_{\mathrm{s}}$ was simply calculated by dividing the internal volume of the processing equipment, $V$, by the exhaust air rate, $Q$, as $t_{\mathrm{s}}=V / Q$. An automatic door located on the front side of the units was used to replace workpieces after machining; the door opened automatically during $10 \mathrm{~s}$ after the machining process finished. In order to further reduce energy costs, the exhaust pump was somewhat synchronized with the machining process, which will be discussed in the "Results" section. The settings used in this study were chosen by the machining company based on the empirically derived oil mist removal efficiency as well as the energy cost; since the measurements were conducted during real manufacturing of automobile parts, it was difficult to change the systems' parameters, such as exhaust flow rate and timing of the automatic door.

Two optical particle spectrometers (OPCs; welas digital 2000; Palas) and an electrostatic mobility spectrometer (EEPS; 
Model 3090; TSI Inc.) were used to measure the number size distribution of the oil mist; measurement diameter were 300-17,000 $\mathrm{nm}$ for the OPCs and 6-560 $\mathrm{nm}$ for the EEPS. A sampling line with an inner diameter of $7 \mathrm{~mm}$ was located $300 \mathrm{~mm}$ upstream of the collecting apparatus; the particles in the exhaust air were sampled in OPC1 and the EEPS using this line and the total sampling flow rate was $15 \mathrm{~L} \mathrm{~min}^{-1}$ ( $5 \mathrm{~L} \mathrm{~min}^{-1}$ for OPC1 and $10 \mathrm{~L} \mathrm{~min}^{-1}$ for the EEPS). The sampling flow velocity $\left(6.5 \mathrm{~m} \mathrm{~s}^{-1}\right)$ was not completely matched to the exhaust air velocity $\left(2.8-16.4 \mathrm{~m} \mathrm{~s}^{-1}\right)$ because of the limitations of the setting. In order to monitor the leakage of oil mist from the apparatus door, OPC2 was set in front of the process apparatus, which is located approximately $200 \mathrm{~mm}$ distance from the door. The three instruments, two OPCs and EEPS, were operated simultaneously in order to measure temporal changes in oil mist at the exhaust duct and at the apparatus door.

The concentration of UFP $(6-100 \mathrm{~nm})$ in the factory was about $2 \times 10^{5}$ particles $\mathrm{cm}^{-3}$. Since the oil mist was sufficiently diffused in the factory, the UFP concentration in the exhaust air from the factory was considered to be similar to the particle concentrations in the workspace.

\section{RESULTS}

\section{Lathe Machining}

Fig. 4 shows the change in the number concentration of airborne particles exhausted from the lathe machining apparatus. The number concentration of particles in the range of 300-500 $\mathrm{nm}$ increased once the machining process started and the ventilation was turned on, which occurred every $50 \mathrm{~s}$ (Fig. 4(c)); this periodic increase was observed by both OPC1 (Fig. 4(a)) and the EEPS (Fig. 4(b)). Based on these results, high concentrations of airborne particles (> $10^{6}$ particles $\mathrm{cm}^{-3}$ ) were generated during the lathe machining process. Considering their size, these oil mist particles are hypothesized to be generated by the nucleation of vaporized machining oil. Fig. 4(d) shows the changes in the number concentration of airborne particles both in the exhaust and in front of the process apparatus. In the exhaust, the total number concentration across the entire size range (6 $\mathrm{nm}$ to $17 \mu \mathrm{m}$ ) exhibited periodic variation with 50-s cycles and the number concentration of the UFP fraction $(<100 \mathrm{~nm})$ was almost identical to that of the total number concentration, which indicates that UFP were the dominant fraction of the airborne particles. The number concentration of the fine particle fraction $(>300 \mathrm{~nm})$ in the exhaust $\left(\mathrm{FP}_{\text {apparatus }}\right)$ was also synchronized with the machining process cycles; however, their concentration was two orders of magnitude less than that of the total and UFP concentrations. However, small peaks, which reached up to about 100 particles $\mathrm{cm}^{-3}$, were found in lathe machining even in the door close as shown in Fig. 4(d). This might be advection of air mass containing high concentrations of particles into the area associated with moving of the surrounding workers.

\section{Gear Cutting}

Fig. 5 shows the change in the number concentration of oil mist exhausted from the gear cutting apparatus. While this process operated without cutting oil, oil mist was still generated and the periodic increase in number concentration corresponded to the timing of the cutting process (Figs. 5(a) and 5(b)). Since the surface temperature of the machining point was not higher than the evaporation temperature of the metal, the airborne particles were considered to be mainly composed of residual lubricating oil. In fact, no thermal damage, such as surface melting or ablation, was seen on the surface of the work. Moreover, the average mobility diameter of the oil mist particles was initially approximately 30-40 nm and increased with processing time (Fig. 5(b)). This increase of particle diameter might be caused by the particle condensation, because the surface of the workpiece was maximum temperature during the cutting and residual oil was not supplied to the machining point. This trend was also observed in the number concentrations of the specific particle size ranges (Fig. 5(d)). UFP concentration was almost identical to the total number concentration. Number concentrations of UFP were rapidly increased within $10 \mathrm{~s}$ after starting the process. After that, number concentrations of UFP was almost constant or slightly decreased with time during the processed. However, number concentrations of FP were gradually increased during the process. There was found a time lag of attaining the maximum number concentrations between UFP and FP. This also suggests the increase of particle diameter during the process time.

The number concentration of $\mathrm{FP}_{\text {front }}$ increased to approximately 1,800 particles $\mathrm{cm}^{-3}$ when the apparatus door was opened. These concentrations were higher than that of lathe machining; the ventilation flow rate during cutting was approximately 6 times higher than during lathe machining. The higher number concentrations of $\mathrm{FP}_{\text {front }}$ in the gear cutting process may be due to the generation of larger particles during the later stage of cutting.

\section{Gear Grinding}

Fig. 6 shows the change in the size distribution of number concentration of particles in the exhaust air into the gear grinding apparatus. During this process, the number concentration of FP (300-1,000 nm) (Fig. 6(a)) was higher than those measured during lathe machining (Fig. 4(a)) and gear cutting (Fig. 5(a)). In contrast, higher number concentrations of UFP were observed in the size ranged from $20-100 \mathrm{~nm}$ (Fig. 6(b)), and the size range with high concentrations were smaller than those in the lathe machining (Fig. 4(b)) and gear cutting (Fig. 5(b)). Since the viscosity of the waterinsoluble oil used in this process is lower than that of oil-inwater emulsion, the high number concentration of particles was attributed to the liquid breakup mechanism. However, UFP were still the dominant fraction of the total number concentration (Fig. 6(d)). When the apparatus door was opened, the $\mathrm{FP}_{\text {front }}$ number concentration increased, which implies that particles leaked from the process apparatus. The magnitude of leakage was highest during this process, because the door was open for a longer period (50 s).

Finally, there is a high possibility that oil mist do not include metal particles or contribution of metal particles are very few in the three processes. The metal particles entrained into oil mist will be considered as future task. 


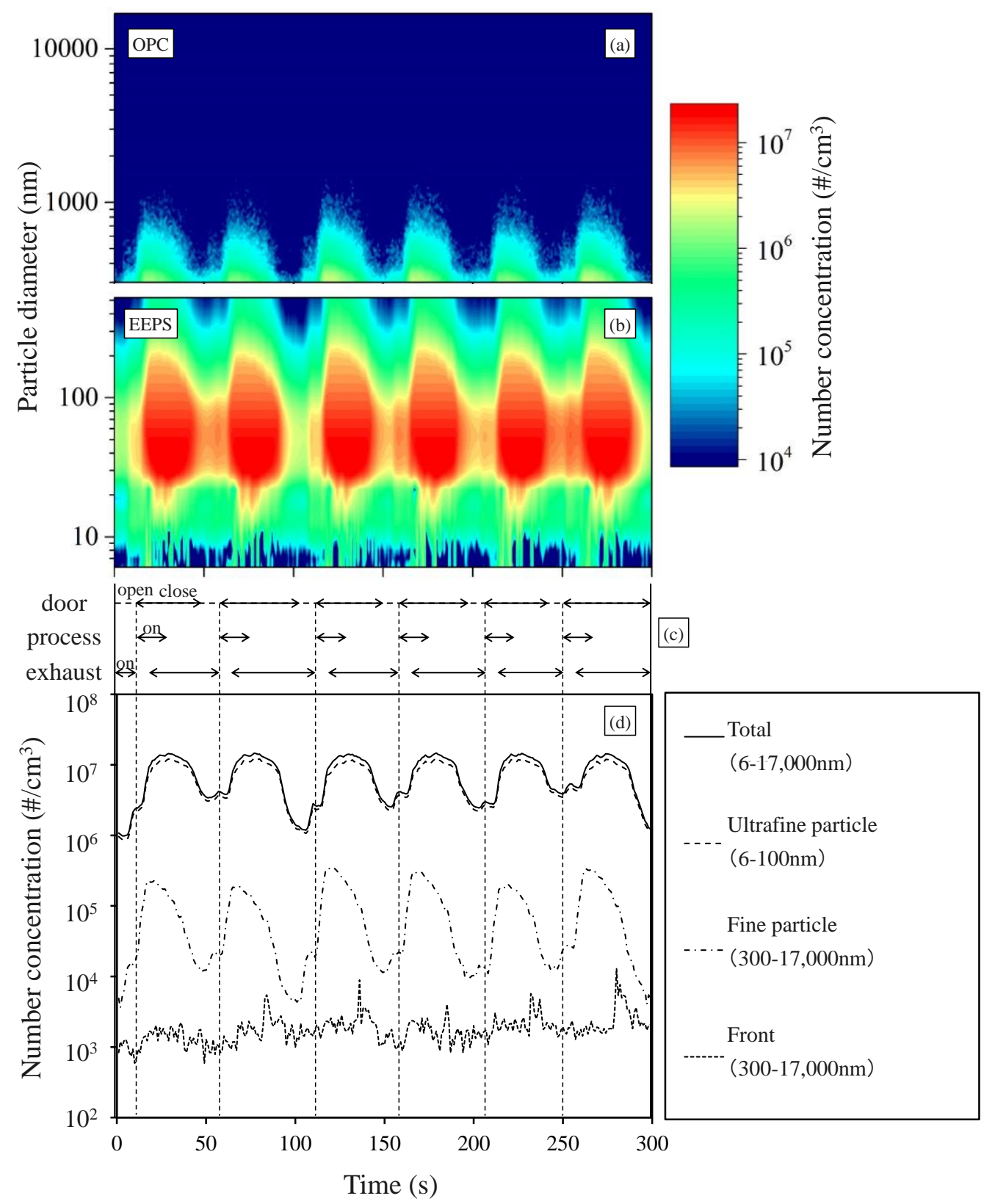

Fig. 4. Change in particle number concentrations by lathe machining: (a) size distribution of particle number concentrations measured by OPC1 (300-17,000 nm), (b) size distribution of particle number concentrations measured by the EEPS (6$560 \mathrm{~nm}$ ), (c) machining process time, (d) number concentrations of UFP and FP in the exhaust and in front of the processing apparatus.

\section{DISCUSSION}

\section{Modeling UFP and FP Number Concentrations in the \\ Process Apparatus}

As mentioned in the previous section, high concentrations of $\mathrm{FP}_{\text {front }}\left(>10^{3}\right.$ particles $\left.\mathrm{cm}^{-3}\right)$ were observed in front of all process units. In order to investigate the effect of oil mist leakage on the workspace air quality, variations in the number concentrations of UFP and FP were calculated using a simplified numerical simulation.

The change in the number concentration of oil mist particles in the process apparatus $\left(N_{\text {in }}\right)$ with respect to time $(t)$ was determined using the following equation:

$$
\frac{\partial N_{i n}}{\partial t}=G-R-L
$$

where $G$ is generation rate of oil mist, $R$ is replacement rate of the ventilation, and $L$ is leakage of oil mist from the apparatus door. $G_{U F P}$ and $G_{F P}$ were estimated by fitting the calculated curve of time variations of number concentrations with experimental data (as shown in Fig. 7). Both $G_{\text {UFP }}$ and $G_{\mathrm{FP}}$ were estimated from the experimental data, and $R$ and $L$ were determined from the following equations: 


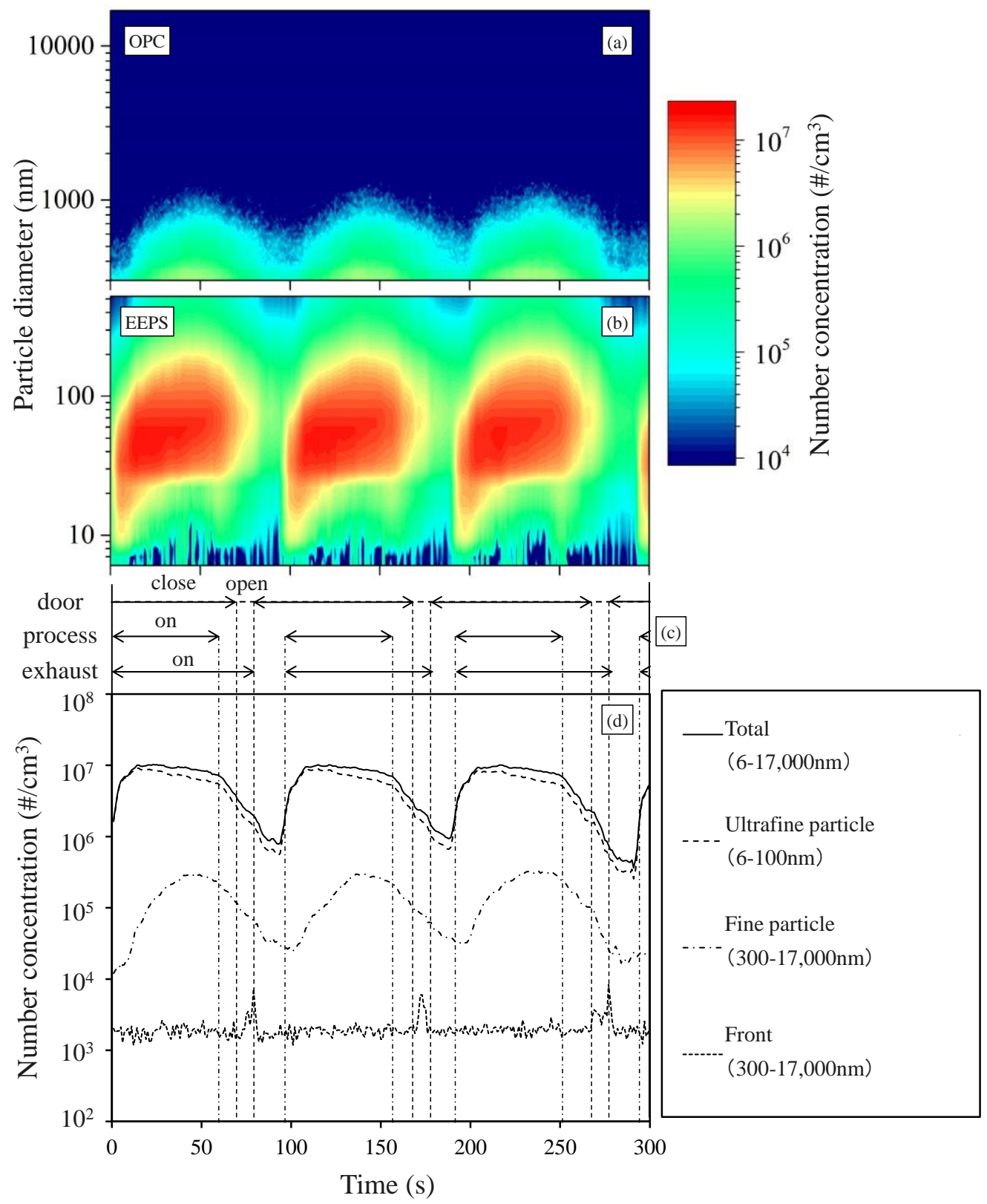

Fig. 5. Change in particle number concentrations by gear cutting: (a) contour plot of particle number concentrations measured by OPC1 $(300-17,000 \mathrm{~nm})$, (b) contour plot of particle number concentrations measured by the EEPS (6-560 $\mathrm{nm})$, (c) machining process time, (d) number concentrations of UFP and FP in the exhaust and in front of the processing apparatus.

$R=\frac{\left\{N_{i n}-N_{b g}\right\}}{V} Q$

$L=\frac{A D\left\{N_{\text {in }}-N_{\text {front }}\right\}}{V X} O C$

where $N_{\text {front }}$ is the number concentrations in front of processed apparatus, $N_{\mathrm{bg}}$ is background concentration measured at front door, $Q$ is the ventilation flow rate, $V$ is the apparatus volume, $A$ is the area of the apparatus door, $D$ is the particle diffusion coefficient, $X$ is the distance between the apparatus door and the center of the apparatus, and $O C$ is a function that indicates when the door is open $(O C=1)$ or closed $(O C=0)$.

The $N_{\text {front }}$ can also be expressed as:

$\frac{\partial N_{\text {front }}}{\partial t}=L=\frac{A D\left\{N_{\text {in }}-N_{\text {front }}\right\}}{V X} O C$

The parameters for the three machining processes are given in Table 2. The measured and simulated UFP and FP concentrations in the apparatus are shown in Fig. 7.

The UFP number concentration exceeded $1 \times 10^{7}$ particles $\mathrm{cm}^{-3}$ when the apparatus door was closed. Estimated production rate of UFP in lathe machining was 


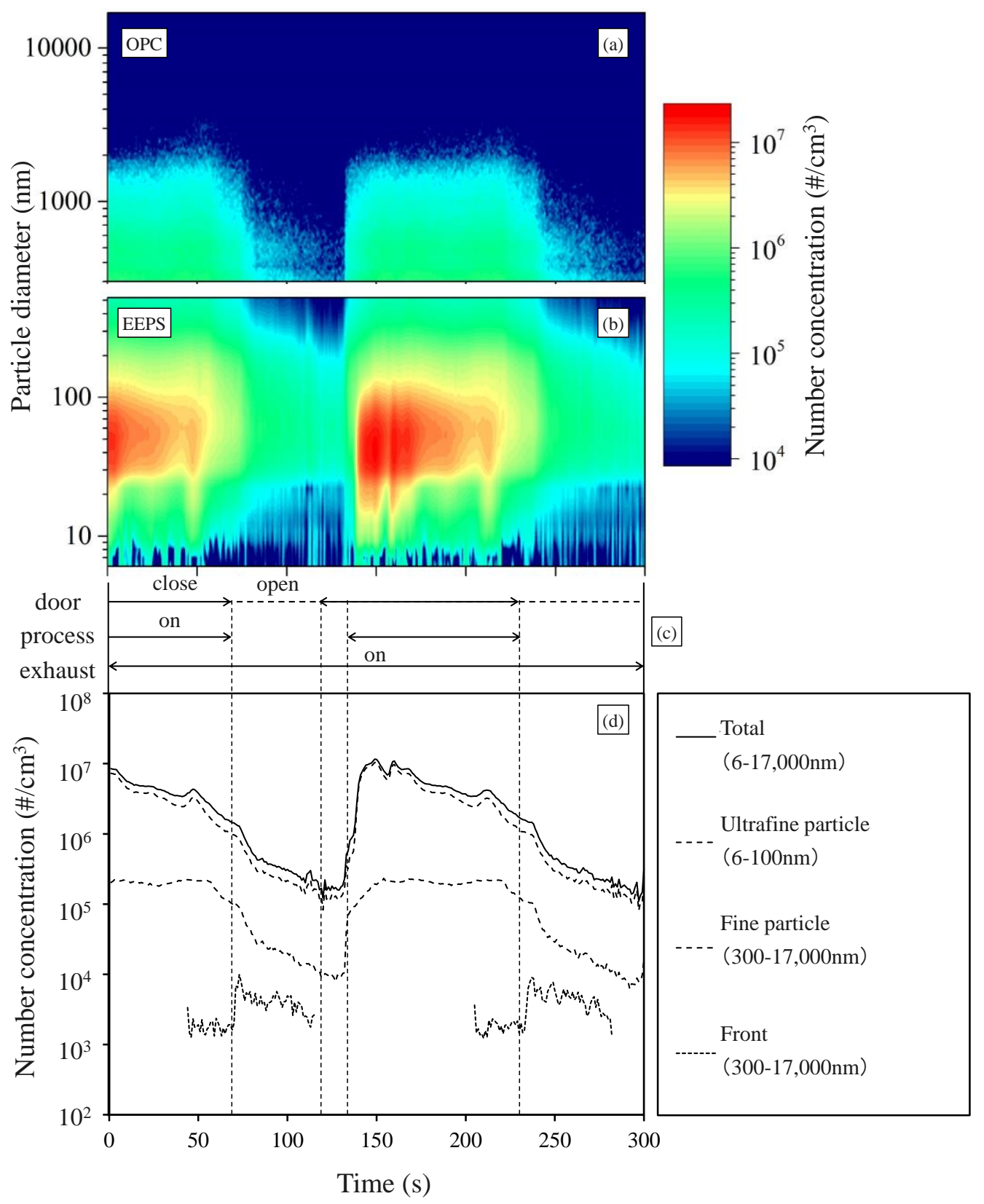

Fig. 6. Change in particle number concentrations by gear grinding: (a) contour plot of particle number concentrations measured by OPC1 $(300-17,000 \mathrm{~nm})$, (b) contour plot of particle number concentrations measured by the EEPS (6-560 $\mathrm{nm}$ ), (c) machining process time, (d) number concentrations of UFP and FP in the exhaust and in front of the processing apparatus.

$1 \times 10^{6} \mathrm{UFP} \mathrm{cm}^{-3} \mathrm{~s}^{-1}$ (Fig. 7(a)). The periodic decrease in the number concentration caused by the ventilation was well represented by the simulation; however, the simulation underestimated the reduction in FP concentration as other mist collection mechanisms, such as inertial or gravitational deposition, were not accounted for in the present simulation.

The UFP number concentrations generated by gear cutting and the estimated production rate was about $2 \times$ $10^{6}$ particles $\mathrm{cm}^{-3} \mathrm{~s}^{-1}$ even though the process did not use oil, which has been attributed to the evaporation and condensation of residual oil (Fig. 7(b)). The simulated FP results of gear cutting (Fig. 7(b)) generally agreed with the measured FP concentrations, which suggests that particle deposition during gear cutting is less significant than during the lathe process because of the higher ventilation flow rate.

In the case of gear grinding process, UFP concentrations were rapidly increased and then gradually decreased within $10 \mathrm{~s}$. The decrease of UFP number concentrations in the observation were not reproduced in the simulation (Fig. 7(c)). The simulated FP results of gear grinding (Fig. 7(c)) also agreed with the measured FP concentrations, which suggests that particle deposition during gear grinding is less significant than during the lathe process because of the higher ventilation flow rate.

In all three processes, the number concentrations of FP gradually decreased to the order of $1 \times 10^{4}$ particles $\mathrm{cm}^{-3}$ 
Table 2. Parameter to estimate ultrafine and fine particle concentrations inside and front of apparatus in numerical simulation.

\begin{tabular}{|c|c|c|c|}
\hline & Lathe machine & Gear cutting machine & Gear grinding machine \\
\hline$V\left[\mathrm{~m}^{3}\right]$ & 1.0 & 2.0 & 3.8 \\
\hline$A\left[\mathrm{~m}^{2}\right]$ & 0.4 & 1.86 & 1.23 \\
\hline$Q\left[\mathrm{~m}^{3} \mathrm{~s}^{-1}\right]$ & 0.05 & 0.29 & 0.31 \\
\hline$x[\mathrm{~m}]$ & 0.2 & 0.2 & 0.2 \\
\hline$D_{\mathrm{UP}}\left[\mathrm{m}^{2} \mathrm{~s}^{-1}\right] @ \mathrm{D} 0.01 \mathrm{~mm}$ & $5.5 \times 10^{-8}$ & $5.5 \times 10^{-8}$ & $5.5 \times 10^{-8}$ \\
\hline$D_{\mathrm{FP}}\left[\mathrm{m}^{2} \mathrm{~s}^{-1}\right] @ \mathrm{D} 0.3 \mathrm{~mm}$ & $4.1 \times 10^{-13}$ & $4.1 \times 10^{-13}$ & $4.1 \times 10^{-13}$ \\
\hline$N_{\text {BG_UP }}\left[\right.$ particles $\left.\mathrm{cm}^{-3} \mathrm{~s}^{-1}\right]$ & $2 \times 10^{5}$ & $2 \times 10^{5}$ & $2 \times 10^{5}$ \\
\hline$N_{\text {BG FP }}\left[\right.$ particles $\left.\mathrm{cm}^{-3} \mathrm{~s}^{-1}\right]$ & $1 \times 10^{3}$ & $1 \times 10^{3}$ & $1 \times 10^{3}$ \\
\hline$G_{\text {UFP }}\left[\right.$ particles $\left.\mathrm{cm}^{-3} \mathrm{~s}^{-1}\right]$ & $1 \times 10^{6}$ & $2 \times 10^{6}$ & $1 \times 10^{6}$ \\
\hline$G_{\mathrm{FP}}\left[\right.$ particles $\left.\mathrm{cm}^{-3} \mathrm{~s}^{-1}\right]$ & $2 \times 10^{4}$ & $6 \times 10^{4}$ & $2 \times 10^{4}$ \\
\hline
\end{tabular}

(a) Lathe machining

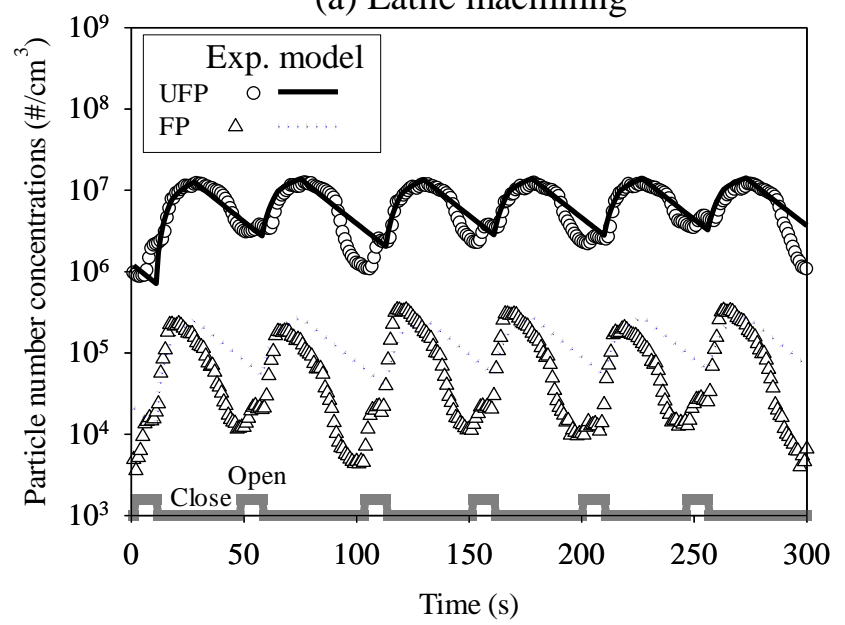

(c) Gear grinding

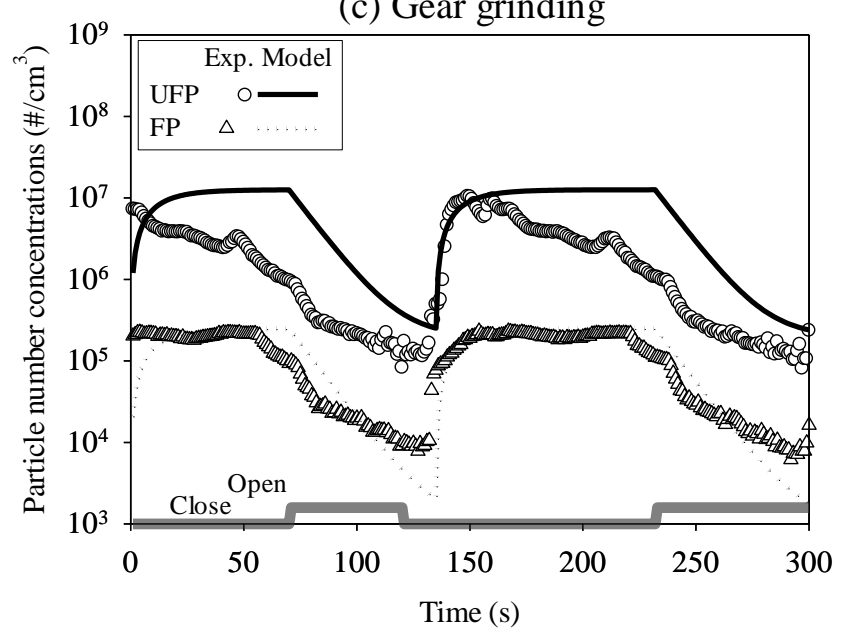

(b) Gear cutting



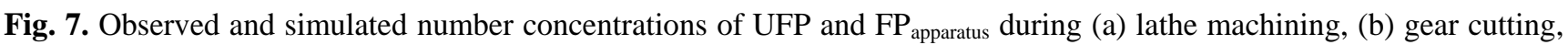
and (c) gear grinding.

over $60 \mathrm{~s}$ after machining stopped; therefore, FP appear to have been efficiently removed by the ventilation. Conversely, the number concentrations of UFP in the process apparatus remained higher than $1 \times 10^{6}$ particles $\mathrm{cm}^{-3}$ even after the apparatus door was opened.

In order to estimate the leakage of the $\mathrm{UFP}_{\text {front }}$ and $\mathrm{FP}_{\text {front }}$ when the apparatus door was open, the size distribution of oil mist in front of the process apparatus was measured using the EEPS (Fig. 8). It is noted that this EEPS does not shown in Fig. 3. In the case of lathe machining (Fig. 8(a)) and gear grinding (Fig. 8(c)), the particle number concentrations increased when the door was opened. The number concentrations of $\mathrm{UFP}_{\text {front }}$ and $\mathrm{FP}_{\text {front }}$ were relatively constant at $1.5 \times 10^{5}$ and $1-3 \times 10^{3}$ particles $\mathrm{cm}^{-3}$, respectively; these 

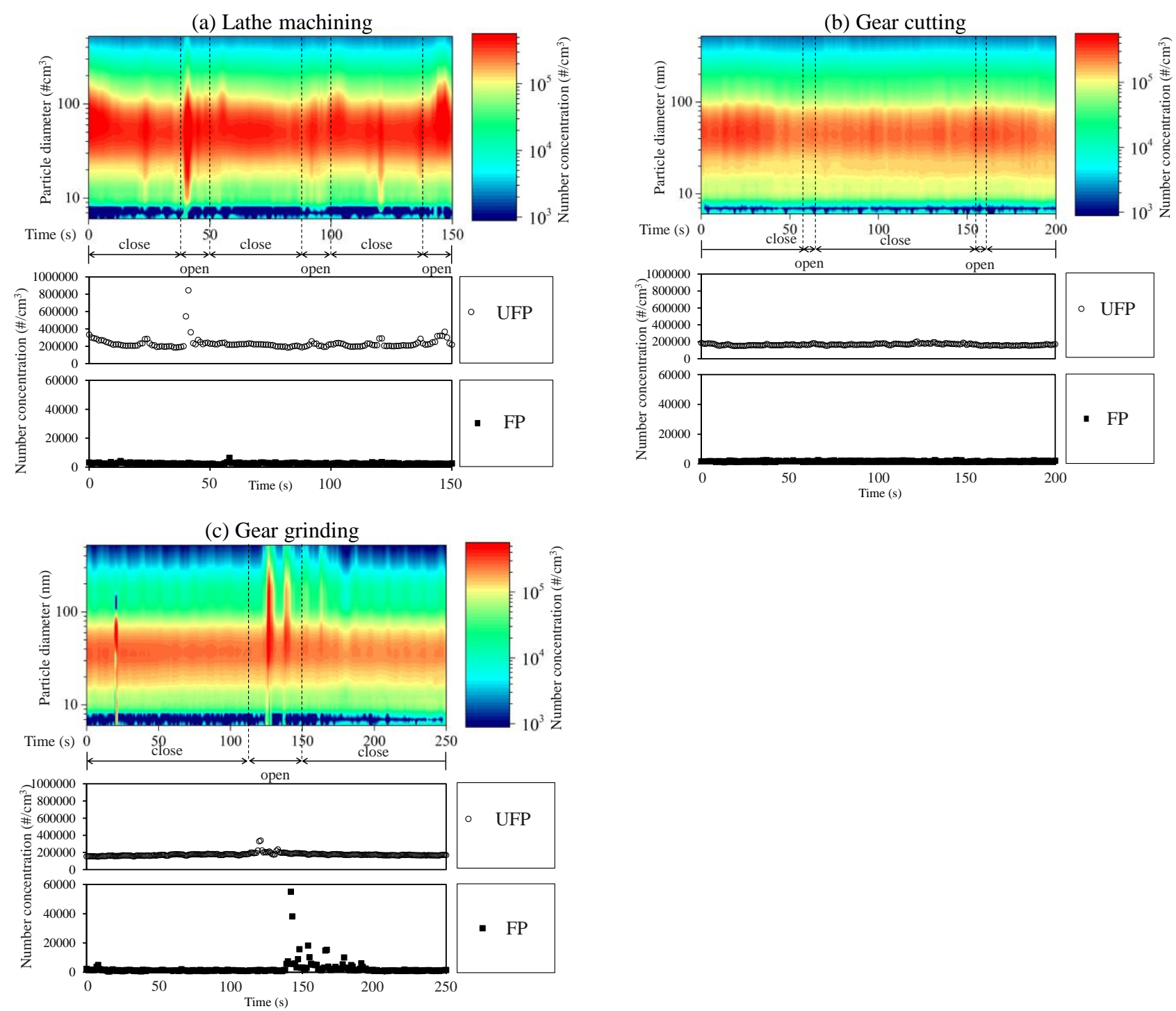

Fig. 8. Leakage of oil mist from the processing apparatus door during (a) lathe machining, (b) gear cutting, and (c) gear grinding. Upper panel show the number size distributions of particles inside the processing apparatus and lower panels show the temporal variation of the $\mathrm{UFP}_{\text {front }}$ and $\mathrm{FP}_{\text {front }}$ concentrations in front of the apparatus door measured by EEPS.

number concentrations were lower than those in the process apparatus $\left(>1 \times 10^{6}\right.$ particles $\left.\mathrm{cm}^{-3}\right)$. Such high $\mathrm{UFP}_{\text {front }}$ concentrations may be released into the workspace from the open door or removed from the processed apparatus as entrained particles during workpiece exchange. Therefore, the oil mist generated by these processes, particularly the high concentrations of UFP $_{\text {front }}$, are expected to cause adverse health effects in the worker such as respiratory problems like bronchitis (Gilbert et al., 2010; Nowak et al., 2019).

\section{Estimation of Leakage and Comparison with Observed Background Concentrations}

In order to investigate the leakage of $\mathrm{UFP}_{\text {front }}$ and $\mathrm{FP}_{\text {front }}$ from the process apparatus, we modeled the particle number concentration in front of the process apparatus. As shown in Eq. (4), the driving force of $\mathrm{UFP}_{\text {front }}$ and $\mathrm{FP}_{\text {front }}$ diffusion is the difference in number concentration between the processing apparatus and ambient atmosphere. The ventilation continued running when the apparatus door was opened to exchange workpieces; therefore, we set the initial number concentrations of $\mathrm{UFP}_{\text {front }}$ and $\mathrm{FP}_{\text {front }}$ to zero and the diffusional leakage rate (against ventilation rate) was estimated in terms of the temporal change in the calculated number concentration in front of process apparatus.

Fig. 9 shows the time profiles of the $\mathrm{UFP}_{\text {front }}$ and $\mathrm{FP}_{\text {front }}$ concentrations in front of the apparatus for the initial condition of $N_{\text {front }}=0$ at $t=0$. The simulation predicted that the $\mathrm{UFP}_{\text {front }}$ and $\mathrm{FP}_{\text {front }}$ concentrations would be less than 300 and $5 \times 10^{-5}$ particles $\mathrm{cm}^{-3}$ after 1 hour, respectively, which implies that the ventilation system could theoretically reduce the diffusional leakage of UFP and FP inside the apparatus when the front door is open. However, considerably higher number concentrations of $\mathrm{UFP}_{\text {front }}$ and $\mathrm{FP}_{\text {front }}$ were measured in front of the apparatus as shown in Fig. 8. As mentioned in the preceding section, $\mathrm{UFP}_{\text {front }}$ and $\mathrm{FP}_{\text {front }}$ may exit from the apparatus associated with the exchange of 


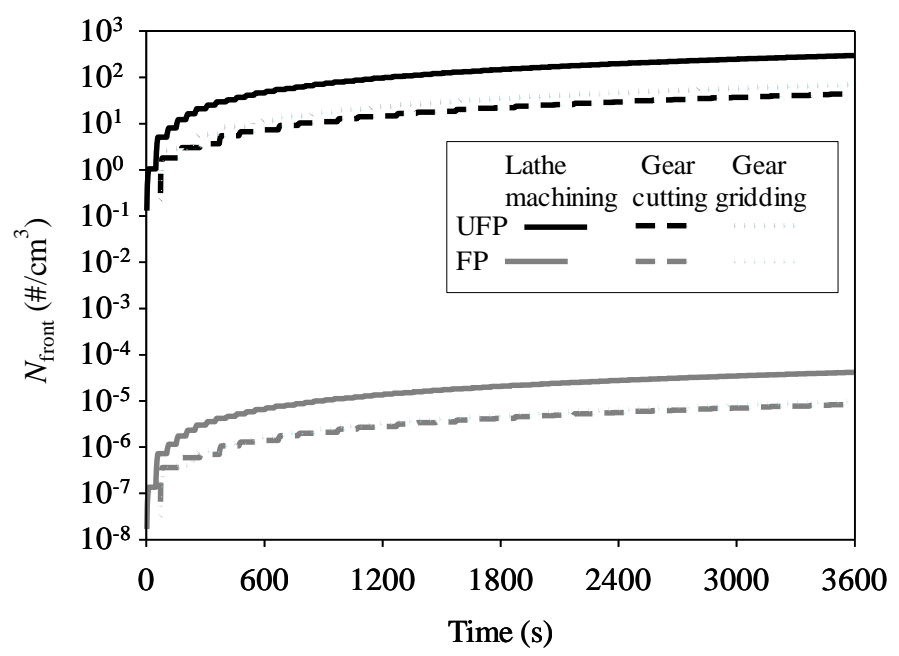

Fig. 9. Calculated leakage of $\mathrm{UFP}_{\text {front }}$ and $\mathrm{FP}_{\text {front }}$ from the processing apparatus to the outside region.

workpieces with entrained particles. Furthermore, it is noted that increase of number concentrations of $\mathrm{UFP}_{\text {front }}$ and $\mathrm{FP}_{\text {front }}$ occurred in front of apparatus during the door closed. We think that the higher concentrations of particles are advected into this area associated with moving of the surrounding workers. It is also noted that the concentrations of UFP in the apparatus were clearly higher when the door was opened (40 s and $130 \mathrm{~s}$; Figs. 8(a) and 8(c)). Therefore, additional preventative measures such as blowing processes and setting air curtain may be necessary to reduce particle entrainment. Moreover, the after-treatment apparatus such as the electrostatic precipitator or centrifugal mist separator in this industrial machining process apparatus may not be sufficient to collect the oil mist or vapor in the exhaust. There are several techniques that can be adopted to reduce the oil mist particles in the exhaust (Saidi et al., 2019). Furthermore, minimum quantity lubrication (MQL) machining is performed to suppress generation of dust (Songmene et al., 2018). Further research is necessary to investigate these two factors and improve air quality in machining workspaces.

\section{CONCLUSIONS}

We measured changes in the number size distributions of oil mist particles in the exhaust and by the door of a processing apparatus used in three typical forms of machining at a metal processing factory. Number concentrations on the order of 1 $\times 10^{7}$ particles $\mathrm{cm}^{-3}$ were found in the exhaust, with UFP $(<100 \mathrm{~nm}$ ) being the dominant fraction. When the apparatus door was opened, the concentrations in front of it displayed a sudden increase, and the effect of this change on the air quality in the workspace was investigated by employing a simplified numerical simulation. Based on the simulation, the particle leakage caused by diffusion was minimal: As cutting terminated upon the door opening, the air flow from this process was considered to be negligible. Therefore, the primary source of leakage from the open door was identified as entrained oil mist on the workpieces as they were transported from inside the processing apparatus to other locations in the factory. In order to improve the air quality in workspaces, preventative measures for reducing particle entrainment must be implemented.

\section{REFERENCE}

Ahrens, W., Jockel, K.H., Patzak, W. and Elsner, G. (1991). Alcohol, smoking, and occupational factors in cancer of the larynx: A case-control study. Am. J. Ind. Med. 20: 477-493. https://doi.org/10.1002/ajim.4700200404

Brahm, J. (2012). Eliminating oil mists in the manufacturing environment. Filtr. Sep. 49: 39-41. https://doi.org/10.1016 /S0015-1882(12)70059-9

Cucu, D. and Lippold, H.D. (1985). High efficiency oil mist filtration with ESP. J. Electrostat. 17: 109-112. https://doi.org/10.1016/0304-3886(85)90013-0

Donaldson, K., Brown, D., Clouter, A., Duffin, R., MacNee, W., Renwick, L., Tran, L. and Stone V. (2002). The pulmonary toxicology of ultrafine particles. J. Aerosol Med. 15: 213-220. https://doi.org/10.1089/08942680232 0282338

Gilbert, Y., Veillette, M., Mériaux, A., Lavoie, J., Cormier, Y. and Duchaine, C. (2010). Metalworking fluid-related aerosols in machining plants. J. Occup. Environ. Hyg. 7: 280-289. https://doi.org/10.1080/15459621003680227

Greg, M.P., Sieber, W.K., O’Brien, D.M., Hughes, R.T., Glaser, R.A. and Catalano, J.D. (2001). Metalworking fluid exposures in small machine shops: An overview. Am. Ind. Hyg. Assoc. 62: 356-370. https://doi.org/10.1080/ 15298660108984638

Hinds, W.C. (1999). Aerosol Technology. A WileyInterscience publication, New York, pp. 349-378.

Jonathan, T. and David, L. (2000). Mist generation during metal machining. J. Tribol. 122: 544-549. https://doi.org/ 10.1115/1.555399

Kazerouni, N., Terry, L.T., Sandra, A.P. and Richard, B.H. (2000). Mortality among workers exposed to cutting oil mist: Update of previous reports. Am. J. Ind. Med. 38: 410-416. https://doi.org/10.1002/1097-0274(200010)38:4 <410::AID-AJIM6>3.0.CO;2-5

Kondo, Y., Kawaguchi, A., Yoshino, H. and Ogita, S. 
(2011). Particle size distribution and aerosol dynamics of oil mist in commercial kitchens. J. Environ. Eng. 76: 547554. https://doi.org/10.3130/aije.76.547

Kubasiewicz, M., Starzynski, Z. and Szymczak, W. (1991). Case-referent study on skin cancer and its relation to occupational exposure to polycyclic aromatic hydrocarbons. II. Study results. Polish J. Occup. Med. Environ. Health 4: 141-147.

Letts, G.M., Raynor P.C. and Schumann, R.L. (2003). Selecting fiber materials to improve mist filters. $J$. Aerosol Sci. 34: 1481-1492. https://doi.org/10.1016/S00 21-8502(03)00102-2

Mackerer, C.R. (1985). Health effects of oil mists: A brief review. Toxicol. Ind. Health 5: 429-440. https://doi.org/ 10.1177/074823378900500304

Massin, N., Bohadana, A.B., Wild, P., Goutet, P., Kirstetter, H. and Toamain, J.P. (1996). Airway responsiveness, respiratory symptoms, and exposures to soluble oil mist in mechanical workers. Occup. Environ. Med. 53: 748752. http://dx.doi.org/10.1136/oem.53.11.748

Nowak, P., Kucharska, K. and Kamiński, M. (2019). Ecological and health effects of lubricant oils emitted into the environment. Int. J. Environ. Res. Public Health 16: 3002. https://doi.org/10.3390/ijerph16163002

Oberdörster, G., (2001). Pulmonary effects of inhaled ultrafine particles. Int. Arc. Occup. Environ. Health 74: 1-8. https://doi.org/10.1007/s004200000185

Robertson, A.S., Weir, D.C. and Burge, P.S., (1988). Occupational asthma due to oil mists. Thorax. 43: 200 205. http://dx.doi.org/10.1136/thx.43.3.200

Saidi, M.N., Djebara, A., Songmene, V. and Bahloul, A.,
(2019). Experimental evaluation of three local exhaust ventilation systems designed to reduce ultrafine dust emission during a polishing process. Aerosol Sci. Eng. 4: 9-17. https://doi.org/10.1007/s41810-019-00050-5

Simpson, A.T., Stear, M., Groves, J.A., Piney, M., Bradley, S.D., Stagg, S. and Crook, B. (2003). Occupational exposure to metalworking fluid mist and sump fluid contaminants. Ann. Occup. Hyg. 47: 17-30. https://doi.org/ 10.1093/annhyg/meg006

Songmene, V., Kouam, J. and Bahloul, A. (2018). Effect of minimum quantity lubrication (MQL) on fine and ultrafine particle emission and distribution during polishing of granite. Measurement 114: 398-408. https://doi.org/10.1016 /j.measurement.2017.10.012

Wang, Y.F., Tsai, P.J., Chen, C.W., Chen, D.R. and Dai, Y.T. (2011). Size distributions and exposure concentrations of nanoparticles associated with the emissions of oil mists from fastener manufacturing processes. J. Hazard. Mater. 198: 182-187. https://doi.org/10.1016/j.jhazmat.2011.10. 028

Zhang, J., Pan, W., Long, Z., Wang, C. and Feng, Z. (2017). Study of the oil mist filtration performance: Pressure drop characteristics and filter efficiency model. Aerosol Air Qual. Res. 17: 1063-1072. https://doi.org/10.4209/aaqr.2 016.06.0258

Received for review, November 23, 2019 Revised, February 18, 2020 Accepted, March 23, 2020 